\title{
Shelter building behavior of Pyrrhopyge papius (Lepidoptera: Hesperiidae) and the use of the Mayfield method for estimating survivorship of shelter-building Lepidopteran larvae
}

\author{
Harold F. Greeney ${ }^{1,3}$; Thomas R. Walla²; Josh Jahner² \& Ryan Berger ${ }^{1}$ \\ 1 Yanayacu Biological Station \& Center for Creative Studies. Cosanga, Napo, Ecuador, c/o Foch 721 y Amazonas, \\ Quito, Ecuador. \\ 2 Department of Biology, Mesa State College. 1100 North Avenue, Grand Junction, Colorado 81501, USA. \\ ${ }^{3}$ Corresponding author. E-mail: revmmoss@yahoo.com
}

\begin{abstract}
Estimating the survivorship of lepidopteran larvae in the field poses many problems, most notably the potential for monitored subjects to simply wander away. Larvae of the family Hesperiidae, however, construct and dwell in shelters built out of leaf tissue on their host plants, return to their shelters between feeding bouts, and build a predictable series of shelters during larval ontogeny. Here we describe the shelter building behavior of Pyrrhopyge papius Hopffer, 1874 from northeastern Ecuador. Subsequently we test the use of the Mayfield method, a widely-used ornithological method for estimating survivorship of nests, to examine its utility for monitoring survival in free-living hesperiid larvae. Pyrrhopyge papius builds three distinct shelter types during its ontogeny. Monitoring of larvae in the field was successful, generating a predicted $16.4 \%$ survivorship from hatching to pupation. We found no significant differences in survivorship between larval shelter types, and only marginally significant differences between years. The Mayfield method of data collection and analysis may be a useful tool for some studies of survivorship in free-living lepidopteran larvae.
\end{abstract}

KEY WORDS. Caterpillar; Ecuador; predation; skipper; survival.

What has become known as the Mayfield method is a simple tool, widely employed by ornithologists to estimate survivorship of bird nests (e.g. GREENEY \& HALUPKA 2008, WANLESS $\&$ Hockey 2008, Khoury et al. 2009). For most studies, nests found active, at any stage, are followed until they fledge or fail. MAYField (1975) and JoHnson (1979) recognized that traditional methods of estimating success rates (proportion of surviving nests) are positively biased because they fail to take into account nests lost early during the nesting cycle. Mayfield, therefore, proposed that nest survivorship should be evaluated based on the probability that any given nest would survive one more day using the equation $1-$ [(number of failed nests)/(total exposure days)]. In this case, "exposure days" are the total number of days that all nests in the sample were active, and thus susceptible to failure.

Once the probability that a nest will survive one more day is known, the estimate is raised to the power of the total number of days in the nesting cycle (i.e., from laying the eggs to fledging of the young). This model makes the assumption that daily nest survival is constant in time. Since then, many additions to the model have solved ways of dealing with biases such as varying intervals between checks, unequal survivorship across time, and effects of observer bias (e.g. BART \& ROBSON 1982, Pollock \& Cornelius 1988, Stanley 2000). More recently computer programs have been developed that expand on these ideas and give a more accurate and biologically informative comparison between samples with appropriate confidence intervals (Dinsmore et al. 2002).

Lepidopteran larvae can be collected and reared in the laboratory in nearly any field situation, and multiple online databases (e.g. Dyer et al. 2010, JANZEN \& Hallwachs 2010) are frequently used for testing evolutionary and ecological paradigms (e.g. StiReman et al. 2005, Novotny et al. 2006, Dyer et al. 2007). Externally feeding lepidopteran larvae are, however, difficult to monitor in situ, in part because of their propensity to move about on or between host plants, and the difficulty of marking individual caterpillars. Thus an inherent assumption in the Mayfield model, that surviving nests (or individuals) have a $100 \%$ chance of detection, is problematic for studies of caterpillar survival. The larvae of over 18 families of Lepidoptera, however, build shelters out of host plant material, spending much of their time inside these shelters (e.g. Scoble 1992, DeVries 1987). One family in which this behavior is particularly well developed is the Hesperiidae, in which larvae follow predictable ontogenetic patterns in the construction of several shelters throughout their development (Lind et al. 2001, Greeney \& Jones 2003, Greeney 2009). Most species build subsequent shelters in close proximity to the one recently vacated, 
and these are easily found and identified once they have been built and occupied. Thus, in many ways, hesperiid larvae may be treated as nests, and monitored daily to provide estimates of survival and/or rates of predation. Here we document ontogenetic changes in larval shelter construction of a common skipper in the eastern Andes of Ecuador, Pyrrhopyge papius papius Hopffer, 1874, and test the application of the Mayfield method for estimating larval survivorship in the field.

\section{MATERIAL AND METHODS}

All work was carried out at the Yanayacu Biological Station and Center for Creative Studies (YBS), Napo Province, eastern Ecuador at $2100 \mathrm{~m}$. Pyrrhopyge papius (Lepidoptera: Hesperiidae; hereafter Pyrrhopyge) has five larval stadia and feeds on Vismia tomentosa (Clusiaceae; hereafter Vismia) in the study area (H.F. Greeney \& A.D. Warren unpublished data). Vismia tomentosa is a $3-10 \mathrm{~m}$ high tree found on the edges of mid- to high-elevation montane forests of South America (EwAN 1962) and is abundant in the study area. Development time of Pyrhopyge, from hatching to pupation is estimated at 110 days (H.F. Greeney unpublished data). During development, larvae build 3-5 leaf shelters in which they rest while not feeding. We described the ontogeny of larval shelter-building behavior by observing larvae in the field from 1999 to 2006. To avoid artifacts of confinement within containers, we described only shelters built under natural conditions using the terminology developed by Greeney \& Jones (2003) and Greeney (2009).

From August to October 2007 and from June to July 2008 we found and monitored Pyrrhopyge larvae in disturbed areas of pasture and road cuts around YBS. Upon encountering a suitable Vismia host tree we exhaustively surveyed all branches within reach. We marked each occupied Pyrrhopyge shelter with a uniquely numbered flag placed on an adjacent branch, recording shelter type and estimating larva age by the width of the head capsule (H.F. Greeney unpublished data). We visited each shelter every 2-3 days, recording the presence or absence of larvae. We examined larvae through the shelter entrance to minimize disturbance. If a larva was present we gently squeezed the shelter to cause movement and ensure it was still alive. If the shelter was found empty we exhaustively searched nearby leaves for the presence of a new shelter. We were easily able to relocate larvae as they switched shelters, predicting their move and new shelter type based on their age and the shelter ontogeny presented below. If we could not locate the larva or it was dead, following MAYFIELD (1975) we set mortality at the mid-way point between the final two checks. As we were interested in isolating mortality apart from parasitism, we would have stopped monitoring any individuals from which parasitoids emerged during the observation period (in this case none), using only the number of exposure days up until their death, but not counting them in the number predated. We ceased monitoring larvae mid-way through the fifth stadium, well before they were expected to leave the final shelter for pupation (see Results: shelter ontogeny).
We used the Mayfield method (MAYFIELD 1975) to calculate the daily survival rate (DSR) of Pyrrhopyge caterpillars. We then compared survivorship between shelter types and calculated 95\% confidence intervals using methods described by JoHnson (1979). As larvae often remained within the same shelter after molting to second instar or after molting to third instar, we compared survivorship between shelter types rather than between instars. While we acknowledge that there may be differences in survivorship based on larval size (which may exclude certain predator size-guilds), we feel such differences are minimal. Thus, as the shelter must be entered or opened by potential predators, the shelter type is a more ecologically relevant category for comparisons of mortality. We analyzed separately the various types of shelters built by Pyrrhopyge during larval ontogeny (see Results: shelter ontogeny). We used rearing information from an ongoing caterpillar project at this site to calculate parasitism rates for this species (Dyer et al. 2010).

\section{RESULTS}

Pyrrhopyge larvae built three distinct shelter types during larval ontogeny. First instars build a man-hole-like circular shelter immediately upon emergence from the egg (Fig. 1). First instar shelters are created by excising a portion of the leaf blade (always away from the leaf margin), and folding it over to meet the upper surface of the leaf. This circular shelter lid is then firmly fixed to the leaf surface with silk, leaving only a small entrance hole which was usually blocked with the larva's head. This shelter type is termed a center-cut shelter by GreEney (2009). Larvae remained in this first shelter after molting to second instar. Soon after molting to third instar, larvae abandoned the first shelter and built a second shelter on the same leaf or, at most, one leaf away. Shelters built by third instars were either of the same type as the first shelter (ca. 30\%) or were of the type termed 2-cut-folds by GREENEY (2009). Center-cut-fold shelters built by third instars were significantly larger than first shelters and were more oval in shape (Fig. 2). Shelters of the second type built by third instars were created by making two separate cuts initiating from the leaf margin and folding the resulting rectangular-shaped flap onto the upper surface of the leaf blade (Fig. 3). Similar to first shelters, second shelters were tightly pressed to the leaf surface with silk except for a small entrance hole that was blocked by the larval head (Fig. 4). Larvae generally molted to fourth instar within their second shelter and built a final shelter type late in the fourth stadium. The final shelter type built by Pyrrhohpyge larvae is termed a multi-leaf-pocket by GREenEY (2009). This shelter type is built by sewing two or more adjacent leaves together with silk (Fig. 5). The resulting pocket is tightly sealed with silk, leaving only a small entrance hole as in previous shelters. Larvae remain in this final shelter until 3-4 days prior to pupation. At this point they leave the final larval shelter and wander up to $10 \mathrm{~m}$ away to construct a similar shelter in which they pupate. Most frequently this shelter was built with the leaves of an adjacent, non-Vismia plant. 

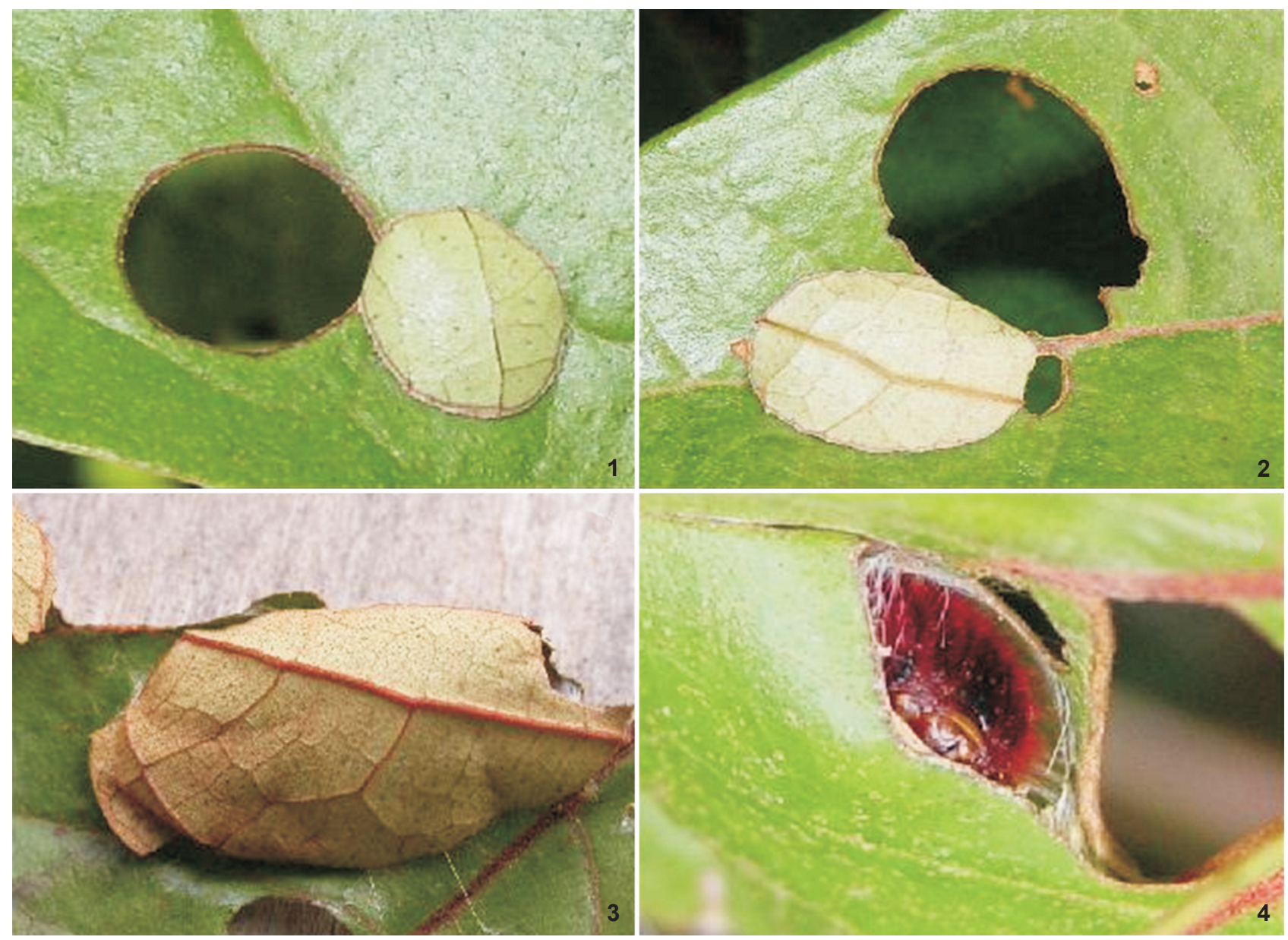

Figures 1-4. Larval shelters of P. papius in eastern Ecuador: (1) shelter built by first instar; (2) second shelter, built by some third instars; (3) shelter built by fourth instars and some third instars, (4) larva in defensive position inside final larval shelter, blocking entrance with head capsule.

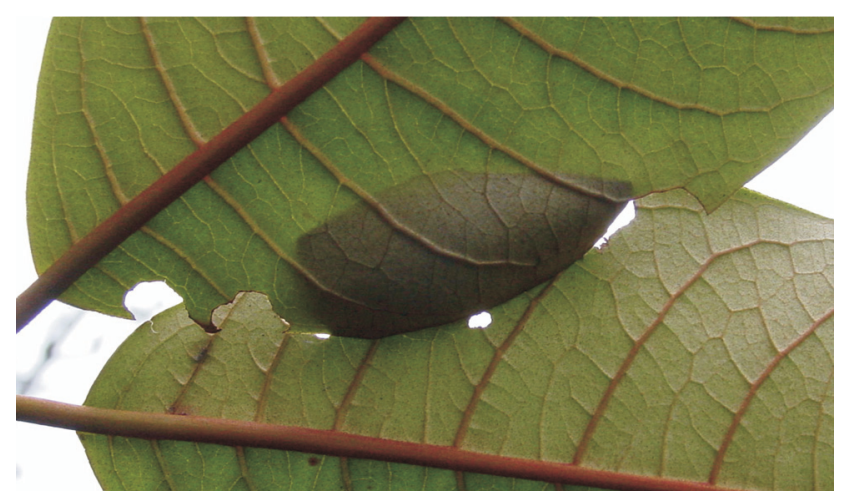

Figure 5. Last instar larval shelter of $P$. papius.

Larval densities were low (generally no more than one per branch or three per tree) and, due to differences in age of adjacent caterpillars we were able to easily distinguish between individuals. Across both years of monitoring, we found and monitored a total of 217 Pyrrhopyge larvae for a combined 4846 exposure days (Tab. I).

After pooling all larvae across all years estimated DSR was $98.4 \%$ (4846 successful days, 79 fatal days, $\mathrm{SE}=0.02$ ). If the larval life-cycle, from hatching to departure from the shelter for pupation, is around 110 days, this gives the prediction that $16.4 \%$ of larvae will survive the larval period they spend inside their shelters. This does not include mortality during wandering or during pupation. There were no significant differences in larval survivorship between the four shelters built during larval ontogeny, even those with the greatest differences in DSR's ( $1^{\text {st }}$ and $2^{\text {nd }}, \mathrm{z}=0.04998, \mathrm{p}=0.6172$ ) (Fig. 6). There was a marginal difference in survivorship between years, pooling all shelter types, with caterpillars surviving better in 2008 ( $\mathrm{z}=$ $2.158, \mathrm{p}=0.031$ ). As both the first and second shelters are cen- 


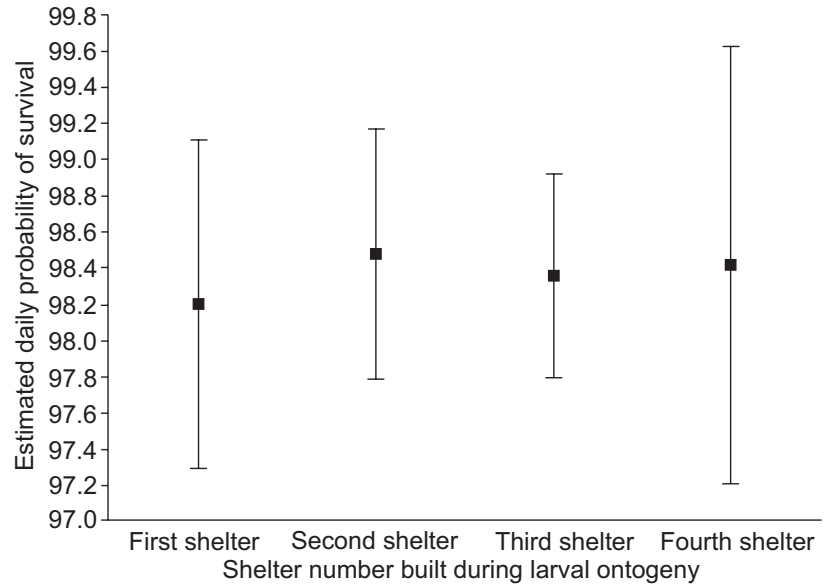

Figure 6. Comparison of the daily probability of survival (with $95 \%$ confidence intervals) of $P$. papius larvae in the field in the four shelters built during larval ontogeny.

ter-cuts (GREeney 2009) we pooled all results from these two shelters and compared them to the other two shelter types, both individually and combined, and found no significant differences. We present DSR calculations for both years and all shelter types in table II. Rearing data from the laboratory (DYER et al. 2010) revealed a parasitism level of $46 \%$ for larvae collected in the field ( $n=47$ larvae).

\section{DISCUSSION}

The construction and use of insect life tables provides important information on the contribution of different mortality factors across life stages, contributing to our understand- ing of ecological and evolutionary processes (CAREY 2001, Peterson et al. 2009), and providing valuable conservation tools (e.g. KaUfman \& WRIGHT 2009). The relative role of predation in larval lepidopteran life tables is, however, often difficult to ascertain due to the difficulty of monitoring mobile life stages in the field and the uncertainty posed by the complete disappearance of larvae which may have variously either fallen from the plant, wandered away, or been removed by a predator. While some studies monitor artificially placed caterpillars in the field (e.g. WikLund \& Friberg 2008), they generate estimates which are biased by undetected wandering of larvae, and are impractical for most tropical lepidopteran larvae which occur in low abundance.

We found an attrition rate of more than $85 \%$ in Pyrrhohpyge during our study. While it is possible that some of our "mortality" was in fact represented by larvae which were knocked from the host plant during inclement weather and found their way back to the appropriate plant (but subsequently survived), we feel this is unlikely in most cases. We suggest that this method is an excellent means of estimating survivorship given the aforementioned challenges associated with larval monitoring. We also note that a large portion of Pyrrhopyge mortality can be attributed to predation. In some cases larvae were found dead inside their shelters appearing to have died due to attack by a predator that did not consume the entire larva or having died of desiccation or viral infection. Thus, our estimates of survival may include a small amount of non-predation related mortality. Similarly, our DSR estimates do not include the potentially dangerous period of wandering prepupation or death during the pupal stage. The proportion of parasitized Pyrrhopyge larvae generated by rearing field-caught larvae in the laboratory was $46 \%$. These two sources of mortal-

Table I. Sample sizes of observed exposure days in the field for caterpillars of $P$. papius in four different shelter types built during the larval stage at Yanayacu Biological Station, Ecuador. [fd] represents fatal days, or the number of larvae which died or disappeared during the observation period and $(\mathrm{n})$ indicates the total number of larvae monitored.

\begin{tabular}{cccccc}
\hline Year & Exp. days type 1 [fd](n) & Exp. days type 2 [fd](n) & Exp. days type $3[\mathrm{fd}](\mathrm{n})$ & Exp. days type $4[\mathrm{fd}](\mathrm{n})$ & Exp. Days Total [fd](n) \\
\hline 2007 & $361[7](15)$ & $639.5[13](34)$ & $1775[33](68)$ & $320.5[6](24)$ & $3096[59](141)$ \\
2008 & $532[9](23)$ & $676[7](29)$ & $422[3](16)$ & $120[1](8)$ & $1750[20](76)$ \\
\hline Total & $893[16](38)$ & $1315.5[20](63)$ & $2197[36](84)$ & $440.5[7](32)$ & $4846[79](217)$ \\
\hline
\end{tabular}

Table II. Daily survival rates (DSR), with SE, and 95\% confidence intervals, of P. papius caterpillars at the Yanayacu Biological Station, Ecuador.

\begin{tabular}{ccccc}
\hline Year & \multicolumn{4}{c}{ Instar } \\
\cline { 2 - 5 } & $1^{\text {st }}$ & $2^{\text {nd }}$ & $3^{\text {rd }}$ & $4^{\text {th }}$ \\
\hline $2007 / D S R \pm S E$ & $98.06 \pm 0.07$ & $97.97 \pm 0.06$ & $98.14 \pm 0.03$ & $98.13 \pm 0.08$ \\
$2007 / 95 \%$ conf. & $96.61-99.51$ & $96.85-99.08$ & $97.50-98.78$ & $96.61-99.64$ \\
$2008 / D S R \pm S E$ & $98.34 \pm 0.05$ & $98.96 \pm 0.04$ & $99.29 \pm 0.04$ & $99.17 \pm 0.08$ \\
$2008 / 95 \%$ conf. & $97.24-99.44$ & $98.19-99.74$ & $98.47-100.11$ & $97.51-100.82$ \\
\hline
\end{tabular}

ZOOLOGIA 27 (6): 867-872, December, 2010 
ity are not necessarily additive (i.e. surviving caterpillars may have hosted parasitoids). Assuming that $46 \%$ of Pyrrhopyge which escape predation are parasitized, we predict that $8.9 \%$ of Pyrrhopyge larvae would survive from hatching to pupation.

As the necessary assumptions of the basic Mayfield model are met by following hesperiid caterpillars in the field, they represent a model system for applying more advanced statistical analyses in comparing survivorship through time and between samples of interest (e.g. Dinsmore et al. 2002). We feel it is important to point out, however, that there is some debate over the use of this method (WeIDINGER 2007), in particular the ways in which data should be collected and analyzed (Manolis et al. 2000). For example, when there are records with uncertain outcomes, excluding these data biases the survival estimate if they do not have the same survival rate as the rest of the observations. Although some of the more sophisticated analyses mitigate different statistical problems such as bias and the power to detect differences among life stages or time periods (Fox 2001, Rotella et al. 2004), the fundamental data collected for these analyses is the same as that required for the Mayfield method. Because of its simplicity and extensive history in ornithology, the Mayfield method is a natural choice for extending the assumptions and data collection methods to a novel group of organisms. We caution readers that the same statistical challenges apply to caterpillars as apply to birds when sample sizes are small or outcomes are uncertain. As such, we recommend careful evaluation of available statistical approaches such as Cox regression, or other current software packages (Rotella et al. 2004) that may provide estimates that are better tailored to correct for the problems generated in the collection of particular data sets.

\section{ACKNOWLEDGMENTS}

We thank the owners and staff of Cabañas San Isidro for access to their private reserve. This study was funded in part by NSF grants DEB-0346729 and DEB-0827793 as well as by the generosity of Matt Kaplan and John Moore and the support of the Lepidoptera Research Foundation, Inc. As always we are grateful for the ongoing encouragement of the PBNHS. This is publication number 216 of the Yanayacu Natural History Research Group.

\section{LITERATURE CITED}

BART, J. \& D.S. Robson. 1982. Estimating survivorship when the subjects are visited periodically. Ecology 63: 1078-1090.

Carey, J.R. 2001. Insect biodemography. Annual Review of Entomology 46: 79-110.

DeVries, P.J. 1987. The butterflies of Costa Rica and their natural history. Princeton, Princeton University Press, vol. $1,327 \mathrm{p}$.

Dinsmore, S.J.; G.C. White \& F.L. Knopf. 2002. Advanced techniques for modeling avian nest survival. Ecology 83: 3476-3488.
Dyer, L.A.; G.L. Gentry; H.F. Greeney \& T.W. Walla. 2010. Caterpillars and parasitoids of the Eastern Andes in Ecuador. Available online at: http://www.caterpillars.org [Accessed: 31.I.2010].

Dyer, L.A.; M.S. Singer; J.T. Lill; J.O. Stireman; G.L. Gentry; R.J. Marquis; R.E. Ricklefs; H.F. Greeney; D.L. Wagner; H.C. MoRaIs; I.R. Diniz; T. A. Kursar \& P.D. Coley. 2007. Host specificity of Lepidoptera in tropical and temperate forests. Nature 448 : 696-699.

EwAN, J. 1962. Synopsis of the South American species of Vismia (Guttiferae). Contributions from the United States National Herbarium 35.5: 293-377.

Fox, G. A. 2001. Failure-time analysis: emergence, flowering, survivorship, and other waiting times, p. 235-266. In: S.M. SCheiner \& J. Gurevitch (Eds). Design and Analysis of Ecological Experiments. New York, Oxford University Press, 415p.

Greeney, H.F. 2009. A revised classification scheme for larval hesperiid shelters, with comments on shelter diversity in the Pyrginae. Journal of Research on the Lepidoptera 41: 53-59.

Greeney, H.F. \& K. HalupKa. 2008. Nesting biology of the Andean Solitaire (Myadestes ralloides) in northeastern Ecuador. Ornitología Neotropical 19: 213-220.

Greeney, H.F. \& M. Jones. 2003. Shelter building in the Hesperiidae: a classification scheme for larval shelters. Journal of Research on the Lepidoptera 37: 27-36.

Janzen, D.H. \& W. Hallwachs. 2010. Dynamic database for an inventory of the macrocaterpillar fauna, and its food plants and parasitoids, of Area de Conservacion Guanacaste (ACG), northwestern Costa Rica. Available online at: http:// janzen.sas.upenn.edu [Accessed: 31.VIII.2010].

Johnson, D.H. 1979. Estimating nest success: the Mayfield method and an alternative. Auk 96: 651-661.

Kaufman, L.V. \& M.G. Wright. 2009. The impact of exotic parasitoids on populations of a native Hawaiian moth assessed using life table studies. Oecologia 159: 295-304.

Khoury, F.; M. Janaydeh \& A.R. Al-Hmoud. 2009. Nest placement and nesting success in two finch species colonizing a recently established plantation in an arid region. Journal of Ornithology 150: 29-37.

Lind, E.M.; M.T. Jones; J.D. Long \& M.R. Weiss. 2001. Ontogenetic changes in leaf shelter construction by larvae of Epargyreus clarus (Hesperiidae), the silver-spotted skipper. Journal of the Lepidopterists' Society 54: 77-82.

Manolis, J.C., D.E. Andersen, \& F.J. Cuthbert. 2000. Uncertain nest fates in songbird studies and variation in Mayfield estimation. Auk 117: 615-626.

MAYFIELD, H.F. 1975. Suggestions for calculating nest success. Wilson Bulletin 87: 456-466.

Novotny, V.; P. Drozd; S.E. Miller; M. Kulfan; M. Janda; Y. Basset \& G.D. Weiblen. 2006. Why are there so many species of herbivorous insects in tropical rainforests? Science 313: 1115-1118. 
Peterson, K.D.; R.S. Davis; L.G. Higley \& O.A. Fernandes. 2009. Mortality risk in insects. Environmental Entomology 38: 2-10.

Pollock, K.H. \& W.L. Cornelius. 1988. A distribution-free nest survival model. Biometrics 44: 397-404.

Rotella, J.J.; S.J. Dinsmore \& T.L. Shaffer. 2004. Modeling nestsurvival data: a comparison of recently developed methods that can be implemented in MARK and SAS. Animal Biodiversity and Conservation 27: 187-205.

Scoble, M.J. 1992. The Lepidoptera. Form, function, and diversity. Oxford, Oxford University Press, 404p.

Stanley, T.R. 2000. Modeling and estimation of stage-specific daily survival probabilities of nests. Ecology 81: 2048-2053.

Stireman III, J.O.; L.A. Dyer; D.H. JANZen; M.S. Singer; J.T. LILl; R.J.
Marquis; R.E. Ricklefs; G.L. Gentry; W. Hallwachs; P.D. Coley; J.A Barone; H.F. Greeney; H. Connahs; P. Barbosa; H.C. Morals \& I.R. DinIz. 2005. Climate unpredictability and parasitism of caterpillars: implications of global warming. Proceedings of the National Academy of Science 102: 17384-17387.

WANLESS, R.M. \& P.A.R. HocKEy. 2008. Natural history and behavior of the Aldabra Rail (Dryolimnas [Cuvieri] aldabranus). Wilson Journal of Ornithology120: 50-51.

Weidinger, K. 2007. Handling of uncertain nest fates and variation in nest survival estimates. Journal of Ornithology 148: 207-213.

WikLund, C. \& M. Friberg. 2009. Enemy-free space and habitatspecific host specialization in a butterfly. Oecologia 157: 287-294.

Submitted: 27.IV.2010; Accepted: 30.VIII.2010.

Editorial responsibility: Pedro Gnaspini 